\title{
Notícia: Professora Zélia Maria Mendes Biasoli-Alves
}

\author{
Cláudia Maria Simões Martinez \\ Universidade Federal de São Carlos \\ Maria Helena Galvão Frem Dias da Silva \\ Universidade Estadual de São Paulo \\ Neucideia Aparecida Silva Colnago \\ Regina Helena lima Caldana ${ }^{1}$ \\ Universidade de São Paulo \\ Silvia Regina Ricco Lucato Sigolo \\ Universidade Estadual de São Paulo
}

\section{News: Professor Zélia Maria Mendes Biasoli-Alves}

O meio científico brasileiro perdeu, no dia 11 de julho passado, não somente uma renomada cientista, que só fez enaltecer e dinamizar a Psicologia e a Educação em nosso país, mas uma pessoa de valor humano incomensurável.

É com muita tristeza, mas também muito orgulho, pelo privilégio da convivência que com ela pudemos ter, que tentaremos tecer em poucas linhas um retrato da nossa querida mestra e amiga.

\section{E mais trabalhara se não fora}

Para tão longo amor, tão curta vida!

Com esses dois versos de Camões, que a Professora Zélia encerrou seu memorial, para o concurso de Livre-Docência junto à Faculdade de Filosofia, Ciências e Letras de Ribeirão Preto da Universidade de São Paulo (FFCLRP-USP), em 1994. Esses versos, sem dúvida, retratam o seu legado deixado a nós. Paixão pelo seu trabalho e pelo conhecimento científico é o que a Professora Zélia sempre transmitiu àqueles que trabalharam consigo.

Aluna da primeira turma da FFCLRP-USP - "picaretas de 1964" eles assim se autodenominavam - sua vida esteve intimamente ligada a essa faculdade, para onde voltou, como docente, dois anos depois de formada:

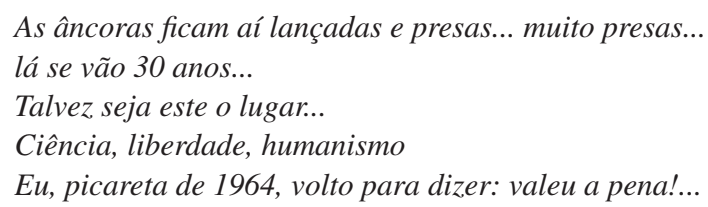

são os versos, agora de uma poesia sua que abre o mesmo memorial.

Sua trajetória, junto à "Filô", como afetivamente chamamos a FFCLRP-USP, foi sempre a de crescimento e ampliação de atividades, de temáticas de trabalho, de parcerias. A

1 Endereço: Universidade de São Paulo, Faculdade de Filosofia Ciências e Letras de Ribeirão Preto, Departamento de Psicologia e Educação, Avenida Bandeirantes, 3900, Campus da USP, Ribeirão Preto, SP, Brasil 14040-901.E-mail: rhlcalda@ffclrp.usp.br professora Zélia, no momento em que se foi, marcava sua presença como Vice-diretora da Faculdade, com expressiva atividade junto à administração geral da USP no campus de São Paulo. Tinha deixado recentemente a coordenação do Programa de Pós-Graduação em Psicologia, após um período de 10 anos em que sustentou, como participante ou em cargo de coordenação, o projeto de criação, implantação e consolidação do Programa; e mais recentemente ainda, coordenou o estabelecimento de um convênio entre o Programa de Pós e a Universidade Federal de Manaus, numa parceria que trouxe mutuamente novas e ricas possibilidades.

Além da atividade didática junto à graduação e pós-graduação, liderava vários projetos de extensão, com forte cunho social. Mantinha intensiva atividade de pesquisa, abarcando temáticas que se caracterizavam como uma extensão cada vez mais ampliada de sua linha de pesquisa inicial. Na pesquisa, além das parcerias "nacionais", principalmente por meio do vínculo com orientandos atuais e ex-orientandos em universidades em diversas regiões no Brasil, desenvolvia projetos conjuntos com pesquisadores no Canadá, Portugal e Itália.

Sua paixão pela pesquisa é o que podemos perceber como móvel de sua atuação na área da Psicologia. Participou ativamente das atividades da Sociedade de Psicologia de Ribeirão Preto (posteriormente Sociedade Brasileira de Psicologia) desde sua fundação, num esforço de crescimento da área e de criação de espaço de intercâmbio e interlocução entre pesquisadores; nessa mesma direção ainda, destaca-se seu trabalho junto à Revista "Paidéia: Cadernos de Psicologia e Educação", revista científica que, ao editorar, levou ao conceito $\mathrm{A}$, e depois até à fase final no processo de indexação no Scielo.

Em termos de temática de pesquisa, sempre teve, como grande área, questões relacionadas à família e à infância: "Socialização: processos, modelos e momentos" é o nome de seu grupo de pesquisa. De início estudou a relação mãe-bebê, passou por questões relacionadas à deficiência, prematuridade, dificuldade de aprendizagem, problemas neurológicos, relação entre família e escola, terceira idade, práticas educativas, e mais recentemente, criança em situação de risco psicossocial. Além disso, vinda de uma tradição e formação inicial na Psicologia Experimental, a partir de seu doutorado trabalhou com estratégia observacional, incorporou gradualmente a entrevista, nas suas diferentes modalidades, e análise 
documental; lançou mão tanto de abordagens quantitativas quanto qualitativas, mantendo pesquisas com desenhos metodológicos diversos, condizentes com a necessidade dos diferentes objetos de estudo.

Esse perfil, que conjugou a pesquisa efetuada de maneira dinâmica, com atuação buscando o fortalecimento das instâncias de divulgação e congregação de pesquisadores, nos parece dar a Professora Zélia um lugar de importância inconteste na consolidação da Psicologia no Brasil.

Ainda mais: detentora de uma sabedoria invejável, por meio de suas pesquisas transitou de forma segura na interdisciplinaridade, trazendo contribuições científicas também em áreas afins à Psicologia, com valiosas ações na formação de pesquisadores e profissionais da saúde e da educação.

Este é um retrato extremamente sumário de suas atividades vinculadas à vida profissional. Se descrever estas atividades já não é tarefa fácil, fazer o mesmo em relação a sua trajetória não seria algo a ser cumprido a contento num curto espaço de tempo. Assim gostaríamos de destacar neste momento, ao lado de sua contribuição à Psicologia, uma outra dimensão, menos visível e pública, que é a da convivência pessoal.

Essa extraordinária pesquisadora conseguia sempre congregar muitos alunos ao seu redor, incentivando-os à investigação científica, de qualidade, com rigor metodológico e que se revertesse em benefício para a sociedade, enriquecendo-se e a todos que trabalhávamos com ela. Nesse sentido, não podemos deixar de assinalar a sua importância na formação de várias gerações de alunos de graduação, bem como daqueles que orientou na pós-graduação. Ela conseguia, como poucos, conciliar as atividades administrativas, os projetos de pesquisa, orientações, preparação de publicações, realização de conferências no Brasil e ao redor do mundo. Sempre procurava atender a todos com o melhor de si.

Na experiência pessoal de contato com a Professora Zélia, somente podemos ressaltar espírito análogo: sua dedicação e empenho em promover aqueles que a circundavam, sempre em meio a imenso entusiasmo e otimismo. Aqui é preciso trazer à tona sua vida pessoal: mãe de cinco filhos, conseguia conciliar trabalho e vida familiar, algo sempre difícil no universo feminino, com alegria ímpar, fornecendo um modelo que sem dúvida procuramos cultivar. No aprendizado de pesquisadores ao seu lado, aprendemos também com ela a sermos mães, amigas, mulheres. Orientar, para ela, era formar ao compartilhar, no espírito de um trabalho artesão no seu melhor sentido, em que se dispõe do tempo que o trabalho em si exige, e não aquele ditado pelo que é externo a ele.

Vida profissional profícua, maternidade profícua, generosidade nos contatos humanos: talvez tudo isso possa ser expresso na idéia de que ela disseminou perspectiva de crescimento por onde circulou. Não por acaso, foi opção da família em homenagem a ela prestada junto à FFCLRP-USP, o plantio de uma jabuticabeira, árvore "xodó" sua, que enraizada num vaso sempre florescia e frutificava. A jabuticabeira foi transferida para o chão da Filô, para que lá continuasse a crescer e a frutificar em tempo que vai muito além daquele dos que com ela conviveram diretamente.

Nunca se esgota uma biografia. A professora Zélia teve uma formação humanística sólida: além de graduada em Psicologia, formou-se também em direito, embora não tenha exercido. Tinha uma paixão particular por letras: além do encanto com o francês, inglês e italiano, a literatura a atraia. Suas poesias são muitas, e num trecho de uma delas (escrita aos 15 anos) ela diz:

\section{Pois é sempre assim que vivo \\ Eternamente a sonhar.}

Dinâmica, entusiasta, inteligente, versátil, ética, única e especial, apaixonada por tudo que fazia, era com prazer que a Professora Zélia ensinava e transmitia o seu saber. Ela nos deixou fazendo o que mais gostava: trabalhando, concretizando seus sonhos. Levá-los adiante é a tarefa que nos cumpre realizar, é a nossa melhor forma de dizer-lhe: "muito obrigada, valeu a pena"! 